Journal of Materials and Environmental Sciences ISSN : 2028-2508

CODEN : JMESCN

Copyright $\odot 2017$

University of Mohammed Premier Oujda Morocco

\title{
Impact in Mineralogical Composition of Geopolymerization Actuation using Fly Ash as the Sole Binder
}

\author{
L. Krishnaraj ${ }^{\text {1* }}$, Grace Mary Abraham ${ }^{2}$, P. T. Ravichandran ${ }^{3}$ \\ $1 *$ Department of Civil Engineering, SRM University, Kattankulathur - 603203, Tamil Nadu, India. \\ 2. Department of Civil Engineering, AmalJyothi College of Engineeing, Koovappally -686518, Kerala, India. \\ 3.Department of Civil Engineering, SRM University, Kattankulathur - 603203,Tamil Nadu, India.
}

Received 07Mar 2017, Revised 07 Jun 2017, Accepted 10 Jun 2017

\section{Keywords}

$\checkmark$ Fly Ash;

$\checkmark$ Geopolymermortar;

$\checkmark$ OvenCuring;

$\checkmark$ SteamCuring;

$\checkmark$ Compressive strength

"L Krishnaraj

krishnarajcivil@gmail.com $+919994782050$

\begin{abstract}
The use of large amounts of cement quantity to increase in carbon dioxide emissions in the world and hence an alternative binding material is required for a sustainable development. The utilization of alumina silicate materials to mostly replace cement content or creation of geopolymer concrete is a noteworthy improvement towards the gainful utilization of modern waste items. Alumino silicates, for example, fly ash, blast furnace slag and metakaolin can be actuated utilizing soluble arrangements of hydroxide and silicates of Sodium or potassium to deliver cement free binders. In this experimental study, Geopolymer mortar specimens were prepared with fly ash and activated with $\mathrm{NaOH} 6 \mathrm{M}$ and $8 \mathrm{M}$ solution. Effect of particle size of raw flyash (RFA), particles sized less than $45 \mu$ sieved fly ash (SFA) concentration of $\mathrm{NaOH}(6 \mathrm{M}, 8 \mathrm{M})$ and varying curing methods and temperatures are curing at ambient temperature, oven curing at $60^{\circ} \mathrm{C}, 80^{\circ} \mathrm{C}$, Steam Curing at $60^{\circ} \mathrm{C}, 80^{\circ} \mathrm{C}$ were the parameters considered. The RFA mortar specimens casted with $8 \mathrm{M} \mathrm{NaOH}$ solution utilizing normal Curing indicates $12 \%$ more compressive strength compared to mortar samples activated with $6 \mathrm{M} \mathrm{NaOH}$ solution. The SFA mortar specimensshows $5 \%$ increase in compressive strength under the same conditions implying the effect of particle size on the compressive strength development. Specimens prepared with $45 \mu$ sieved fly ash developed higher strength compared to specimens prepared with raw fly ash. In the present study there is a particular instance of a conceivable modern use of these new materials in the segment of precast industry.
\end{abstract}

\section{Introduction}

Geopolymer is an alkaline based binder materials formed in secondary cementitious materials, for example, fly ash and rice husk ash. In polymerization process, when a basic arrangement is utilized to respond with the silica and the alumina from the raw material [1,2]. The polymerisation process work under alkaline condition on Si-Al minerals under takes a quick substance initiation, which gave the polymeric chain in the method for three dimensional and ring structure comprising of Si-O-Al-O bonds [3-5].

In geopolymerization process the alumino silicate kaolinite reacts with $\mathrm{NaOH}$ at $100-150^{\circ} \mathrm{C}$ and polycondenses into hydrated sodalite (a tecto-alumino-silicate), or hydro-sodalite. The reaction mechanism is shown below in equation (1):

$$
\begin{aligned}
& \mathrm{Si}_{2} \mathrm{O}_{5}, \mathrm{Al}_{2}(\mathrm{OH})_{4}+\mathrm{NaOH} \Rightarrow \mathrm{Na}(-\mathrm{Si}-\mathrm{O}-\mathrm{Al}-\mathrm{O}) \mathrm{n} \\
& \text { Kaolinite }
\end{aligned}
$$

Geopolymerisation (Figure 1) process involves reaction under alkaline solution condition on $\mathrm{Si}-\mathrm{Al}$ minerals, that shows in a polymeric chain with three dimensional and ring structure consisting of Si-O-Al-O bonds as shown below [6-9]:

$$
\mathrm{Mn}\left[-\left(\mathrm{SiO}_{2}\right) \mathrm{z}-\mathrm{AlO}_{2}\right] \mathrm{n} . \mathrm{wH}_{2} \mathrm{O}_{5}
$$

Where,M- The alkaline element such as potassium, sodium or calcium; the symbol shows presence of a bond and $\mathrm{n}$ - polymerisation degree; $\mathrm{z}-1,2,3$, or more. 


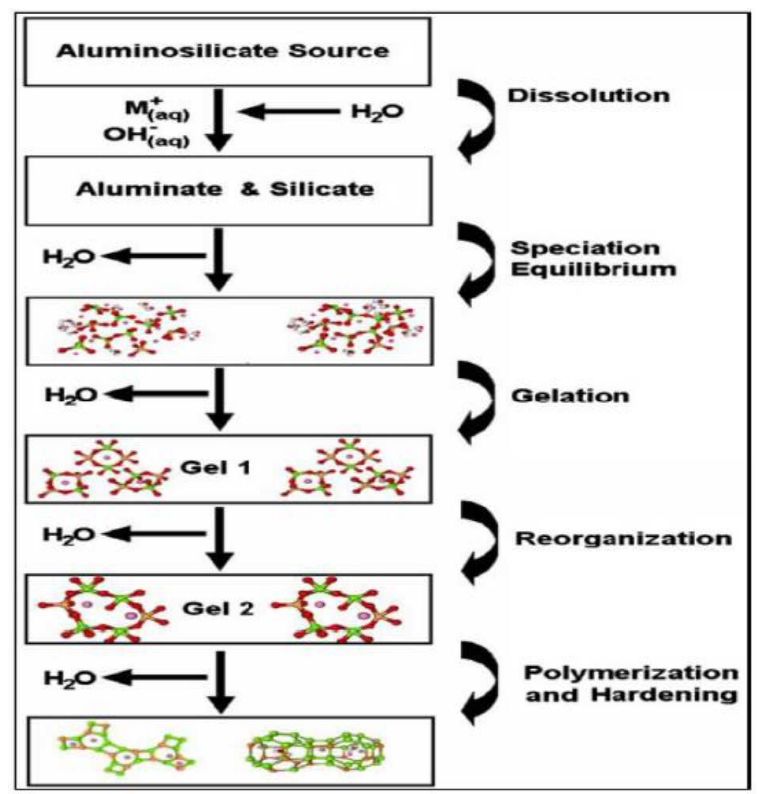

Figure 1: Geo Polymerization Process

The schematic formation of geopolymer mortar specimen shown is in equations (2) and (3).

$$
\begin{array}{lc}
\mathrm{n}\left(\mathrm{Si}_{2} \mathrm{O}_{5}, \mathrm{Al}_{2} \mathrm{O}_{2}\right)+2 \mathrm{nSiO}_{2}+4 \mathrm{nH}_{2} \mathrm{O}+\mathrm{NaOH} & \mathrm{Na}++\mathrm{n}(\mathrm{OH})_{3}-\mathrm{Si}-\mathrm{O}-\mathrm{Al}-\mathrm{O}-\mathrm{Si}-(\mathrm{OH})_{3} \\
(\mathrm{Si}-\text { AlMaterials }) & (\mathrm{OH})_{2}
\end{array}
$$

(Geopolymerprecursor)

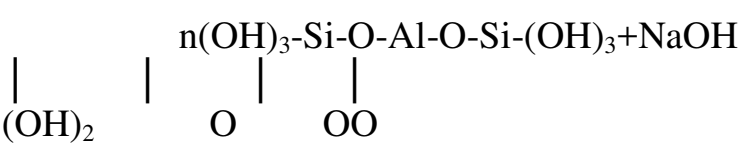

$(\mathrm{Na}+\mathrm{K})-(-\mathrm{Si}-\mathrm{O}-\mathrm{Al}-\mathrm{O}-\mathrm{Si}-\mathrm{O}-)+4 \mathrm{nH}_{2} \mathrm{O} \quad-----(3)$

(Geo polymer backbone)

From the equation (2) observed that, the water is released when the chemical reaction starts which is results the formation of geopolymers. This water is removed from geopolymer matrix process during the curing periods, decrease theporousholes in the geopolymer matrix. This process will ensure that the performance of geopolymers increases and also, the chemical reaction plays important role which enhance the workability to the mortar during handling process $[10,11]$.Reactivity of natural pozzolan might be increased by prolonged grinding, thermal activation, chemical activation, alkali activation. Reduction in particle size directly affects the reactivity of fly ash, which is evident from the testing of mortar specimens[12-14].The method of curing adoptedplays an active role in the strength development of geopolymerspecimens prepared utilizing fly ash. A higher curing temperature does not guarantee higher 28 day compressive strength[15]. The oven and steam curing time can be restricted to 24hours since rate of strengthdevelopmentis high in this period.

In the present study, compressive strength of geoploymer mortar specimens prepared with high concentration of alkali activator has been determined. The effect of sieved fly ash over the raw fly ash geopolymer mortar and effect of temperature and curing methodsis considered.

\section{Experimental Work}

\subsection{Materials}

The fly ash is collected from Neyveli, Tamil Nadu was utilized as a part of present work, which is Class C fly ash as indicated by the ASTM C 618 [16].The collected class C fly ash is termed as raw Fly Ash (RFA).The RFA material passing through a45 $\mu$ sieveis termed as Sieved Fly Ash (SFA). Sodium hydroxide solution is the sole alkaline activator.Alumino silicate materials are more soluble in it sodium based solutions and it is cheaper than Potassium-based solutions. The sodium hydroxide $(\mathrm{NaOH})$ solution was prepared by diluting the pellets in distilled water. Ennoresandof Grade I, Grade II and Grade III conforming to IS 650:1991[17] was collected from Tamil Nadu Minerals Limited mixed in equal proportion is used for the preparation of mortar cubes. 


\subsection{Preparation of Geopolymer Specimens}

The mortar specimens were prepared completely RFA and SFA without cement. The $\mathrm{NaOH}$ alkali activated solution were prepared with 6 Molarity and 8 Molarity concentrations. The binder to ratio used to prepare the mortar cubes is 1:2.75. The mix ratio is adopted as per the ASTM C 270. The water to binder ratio were taken based on the normal consistency value according to IS 4031: part-4 [18]. The three different curing methods are Normal, Steam and Oven curing with $60^{\circ} \mathrm{C}$ and $80^{\circ} \mathrm{C}$ temperature were used for curing the specimens. The mortar specimens were prepared with the sand and fly ash samples are mixed until the mixture is thoroughly blended for 5 minutes. The required amount of the alkali is added based on normal consistency value and mixing is done thoroughly through Hobart mortar mixer according to the IS4031. The $50 \mathrm{~mm}$ size of steel moulds is filled with mortar in two layers with proper compaction. Three mortar cube specimens were prepared for each mix combination and curing method to determine the compressive strength of mortar cubes.

\subsection{Curing and Testing of Mortar specimens}

The RFA and SFA sample basic test properties are Blaine's fineness test, physical properties and chemical properties test was performed according the IS1727:1984. The mortar cube specimens were cured with three unique types curing like Normal, Steam and oven curing. The cubes for oven and steam curing were wrapped by aluminum thwart sheet before putting in the oven for 24 hours following 2 hours of after casting kept in oven at $60^{\circ} \mathrm{C}$ and $80^{\circ} \mathrm{C}$. Demoulding of cubes is done following two hours of the predetermined curing time frame. For steam curing, the cubes were put for 24 hours in the steam curing machine at $60^{\circ} \mathrm{C}$ and $80^{\circ} \mathrm{C}$. Demoulding is done following four hours of the required curing time frame. For ordinary (curing at encompassing temperature) the mortar cubes are demoulded following 24 hours length from the season of casting. Amid curing of geopolymer mortars examples at elevated temperatures, test specimens are to be wrapped and afterward sealed. This precautionary measure has been taken keeping in mind the end goal to keep intemperate loss of dampness from the specimens during curing. The compressive strength for the cubes arranged with RFA and SFA mortar cubes were conducted at age of $3,7,14,28$ days subsequent to casting. The mortar cubes were tried in determined age understanding with ASTM C109 [19].

\subsection{Microstructural studies}

The microstructural behavior characteristics of Raw fly ash and Sieved fly ash were examined utilizing a X-ray diffraction characterization strategy to locate the crystalline size of the quartz stages by utilizing a quickening voltage of $30 \mathrm{kV}$ and a current of $20 \mathrm{~mA}$. The specimens examined at a speed of 2 deg.min- 1 in the $2 \theta$ territory from 10 to $70^{\circ}$. The microstructures of raw fly ash and sieved fly ash samples utilized as a part of this study are investigated utilizing an examining scanning electron microscope(SEM) to find out the basic organization, morphology characters and surface [11-13].

\section{Results and Discussions}

\subsection{Basic Property Test}

The fundamental property test are Specific gravity, normal consistency, particle size analysis of RFA and SFA materials were tried. The physical and chemical composition of RFA and SFA material test outcomes appeared in Table 1.

Table 1: Physical and Chemical Composition of materials

\begin{tabular}{|l|c|c|}
\hline \multicolumn{1}{|c|}{ Composition } & RFA & SFA \\
\hline Silicon Dioxide $\left(\mathrm{SiO}_{2}\right), \%$ & 35.17 & 34.91 \\
\hline Aluminum Oxide $\left(\mathrm{Al}_{2} \mathrm{O}_{3}\right), \%$ & 27.6 & 27.8 \\
\hline Iron Oxide $\left(\mathrm{Fe}_{2} \mathrm{O}_{3}\right), \%$ & 6.84 & 7.10 \\
\hline Sum of $\mathrm{SiO}_{2}, \mathrm{Al}_{2} \mathrm{O}_{3}, \mathrm{Fe}_{2} \mathrm{O}_{3}, \%$ & 69.61 & 69.81 \\
\hline Calcium Oxide $(\mathrm{CaO}), \%$ & 19.41 & 18.87 \\
\hline Magnesium Oxide $(\mathrm{MgO}), \%$ & 1.72 & 1.71 \\
\hline Sulphur Trioxide $\left(\mathrm{SO}_{3}\right), \%$ & 4.67 & 4.37 \\
\hline Potassium $\left(\mathrm{K}_{2} \mathrm{O}\right), \%$ & 0.25 & 0.2 \\
\hline Loss on Ignition, \% & 2.72 & 3.68 \\
\hline Specific Gravity & 2.62 & 2.55 \\
\hline Blaine's Specific Surface Area $\left(\mathrm{cm}^{2} / \mathrm{gm}\right)$ & 2657 & 4749 \\
\hline Mean diameter particle size in $\mu$ & 21.35 & 8.62 \\
\hline
\end{tabular}


The Blaine's fineness value was $2657 \mathrm{~cm}^{2} / \mathrm{gm}$ for RFA and $4749 \mathrm{~cm}^{2} / \mathrm{gm}$. For SFA Blaine's values were increases while comparing with RFA samples due to the fineness of SFA samples. The normal consistency tests weredone on the RFA and SFA with 6 and $8 \mathrm{M}$ of $\mathrm{NaOH}$ solution. It is seen that the consistency of RFA with the use of $\mathrm{NaOHsolution}$ of 6 and $8 \mathrm{M}$ is $51.25 \%$ and $48.25 \%$ individually. The consistency of SFA with the expansion of $\mathrm{NaOH}$ solution of 6 and $8 \mathrm{M}$ is $47.5 \%$ and $45 \%$ individually. From the consistency test values it is watched that as the concentration of the alkali was increased, the consistency decreased. These results prove the expanded dissolvability of the alumino silicate material in fly ash at higher groupings of the alkaline solution [15]. The RFA and SFA sample chemical composition test results arecompared and it is presented in Table 1. From the results, it is observed that,thechemicalcomposiotion of SFA values are almost similar to that of RFA. However the specific gravity and the particle mean size is decreased in SFA. Considering the specific surface of SFA, it is increased from $2657 \mathrm{~cm}^{2} / \mathrm{gm}$ to $4749 \mathrm{~cm}^{2} / \mathrm{gm}$.

\subsection{Effect of Change in Molarity of Activator Solution}

The RFA tests with $\mathrm{NaOH} 6 \mathrm{M}$ and $8 \mathrm{M}$ solution used to prepare mortar cubes to decide the compressive strength at the testing age of 3, 7, 14 and 28th day. The test outcomes arepresented in (Figure 2 and 3) respectivly. 8M oven Cured specimensat $60^{\circ} \mathrm{C}$ and $80^{\circ} \mathrm{C}$ gives $49 \%$ and $32 \%$ higher strength in comparison to $6 \mathrm{M}$ oven cured mortar samples. The $8 \mathrm{M}$ steam Cured specimensat $60^{\circ} \mathrm{C}$ and $80^{\circ} \mathrm{C}$ gives $6 \%$ and $12 \%$ higher compressive strength in comparison to $6 \mathrm{M}$ steam cured mortar samples. The $8 \mathrm{M}$ normal cured specimenshows $12 \%$ increase in compressive strength in comparison to $6 \mathrm{M}$ samples cured normally.

The test results of SFA mortar cubes are shown in (Figure 4 and 5). It is seen that the $8 \mathrm{M}$ oven curing with $60^{\circ} \mathrm{C}$ and $80^{\circ} \mathrm{C}$ gives $15 \%$ and $21 \%$ higher compressive strength compared to $6 \mathrm{M}$ oven cured mortar samples. The $8 \mathrm{M}$ steam Cured samples in $60^{\circ} \mathrm{C}$ and $80^{\circ} \mathrm{C}$ gives $3 \%$ and $6 \%$ higher compressive strength compared to $6 \mathrm{M}$ steam curing mortar samples. The $8 \mathrm{M}$ normal Cured samples give $5 \%$ higher compressive strength compared to $6 \mathrm{M}$ samples [21,11]. In early stage the Oven curing and steam curing gives more compressive strength in comparison with the normal curing mortar specimens, it may be due to the curing of sample in elevated temperature. Due to the increase in temperature there is a possibility of changes the polymerization process and it offers the better binding properties of between the particles in mortar specimen.

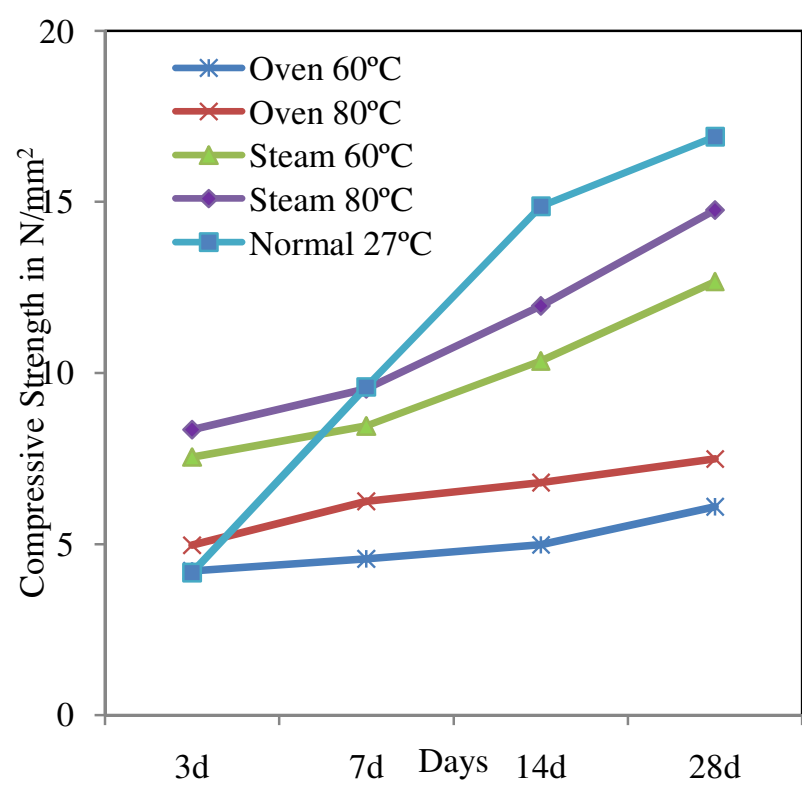

Figure 2: Compressive strength of RFA mortar specimens with 6M Alkali solution

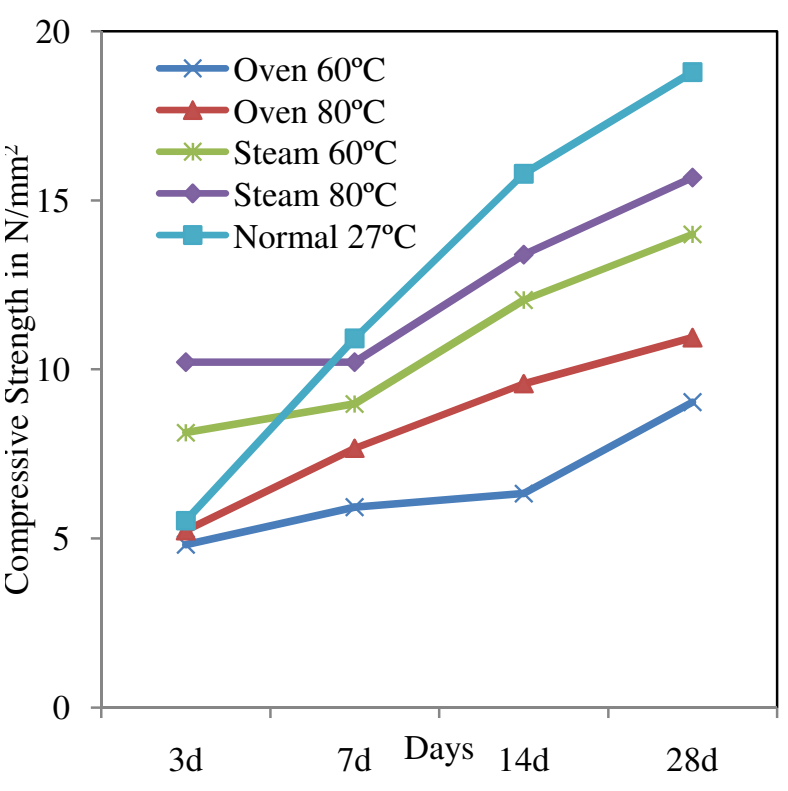

Figure 3: Compressive strength of RFA mortar specimens with $8 \mathrm{M}$ Alkali solution

\subsection{Effect of particle size on compressive strength}

The (Figure 6 and 7) represent the effect of of particle size reduction on 28 day compressive strength of mortar cubes prepared with RFA and SFA in $6 \mathrm{M}$ and $8 \mathrm{M}$. It is seen that the SFA mortar cubes prepared in $6 \mathrm{M}$ solution and cured in oven at $60^{\circ} \mathrm{C}$ and $80^{\circ} \mathrm{C}$ mortar gives 30 and $37 \%$ higher compressive strength compared to RFA specimens. The SFA mortar cubes prepared in $8 \mathrm{M}$ solution and cured in oven at $60^{\circ} \mathrm{C}$ and $80^{\circ} \mathrm{C}$ show $23 \%$ and $6 \%$ higher compressive strength compared to RFA specimens. 


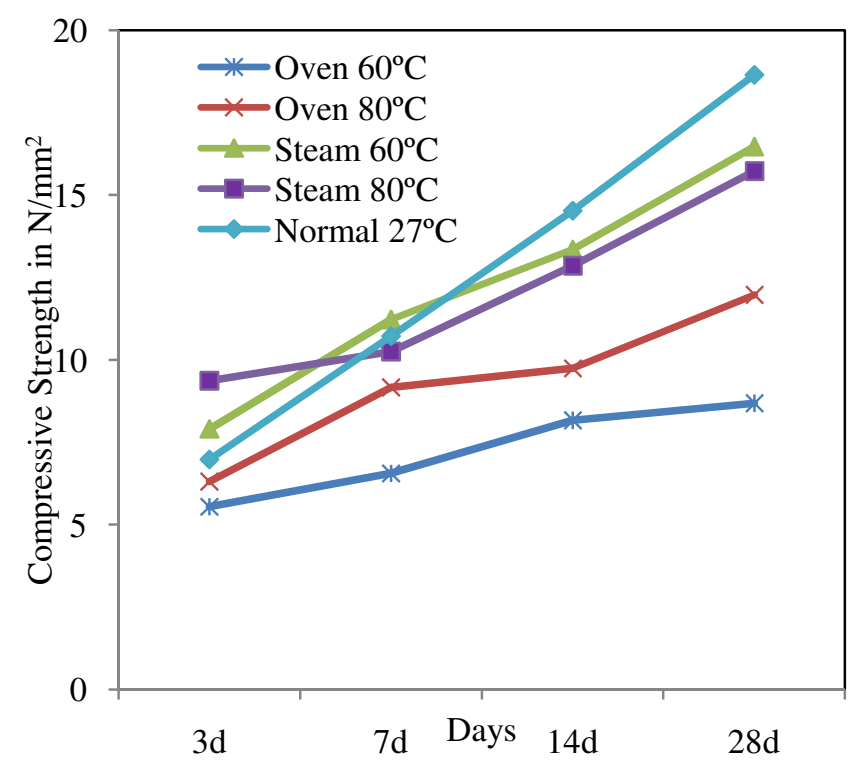

Figure 4: Compressive strength of SFA mortar specimens with $6 \mathrm{M}$ Alkali solution

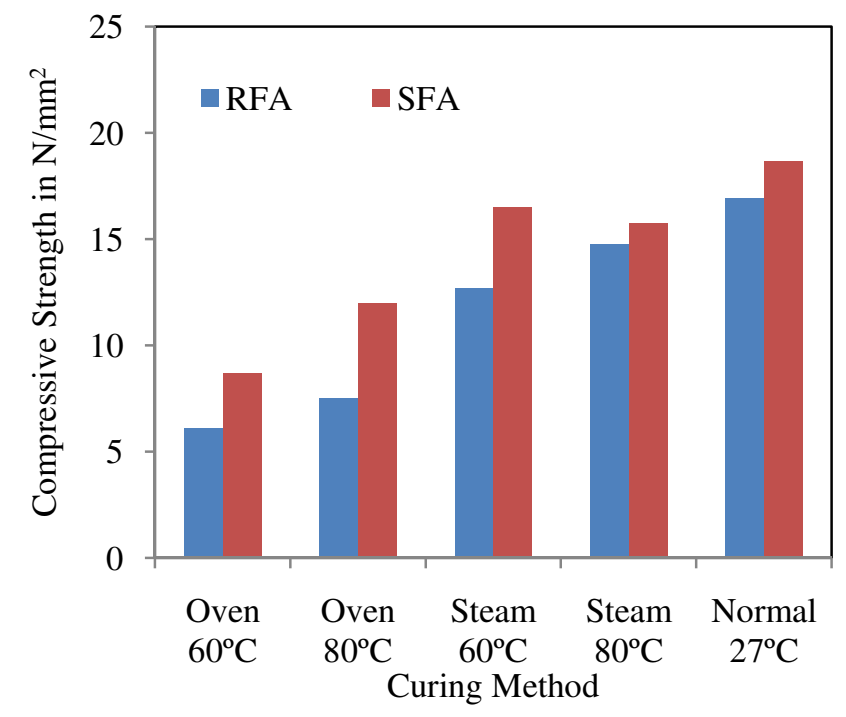

Figure 6: Compressive strength of $6 \mathrm{M}$ with Different curing Methods at 28 days

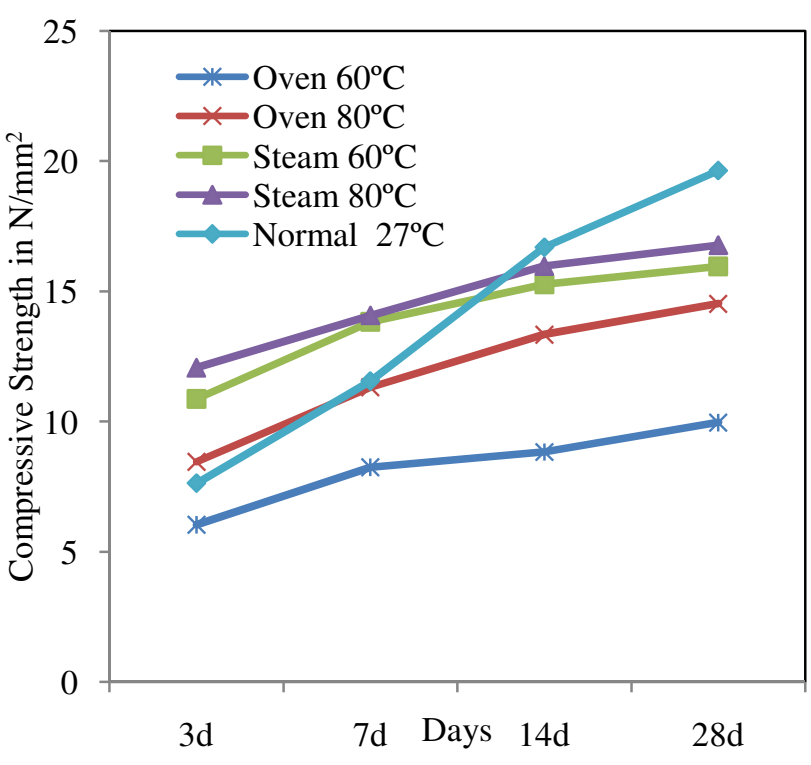

Figure 5: Compressive strength of SFA mortar specimens with 8M Alkali solution

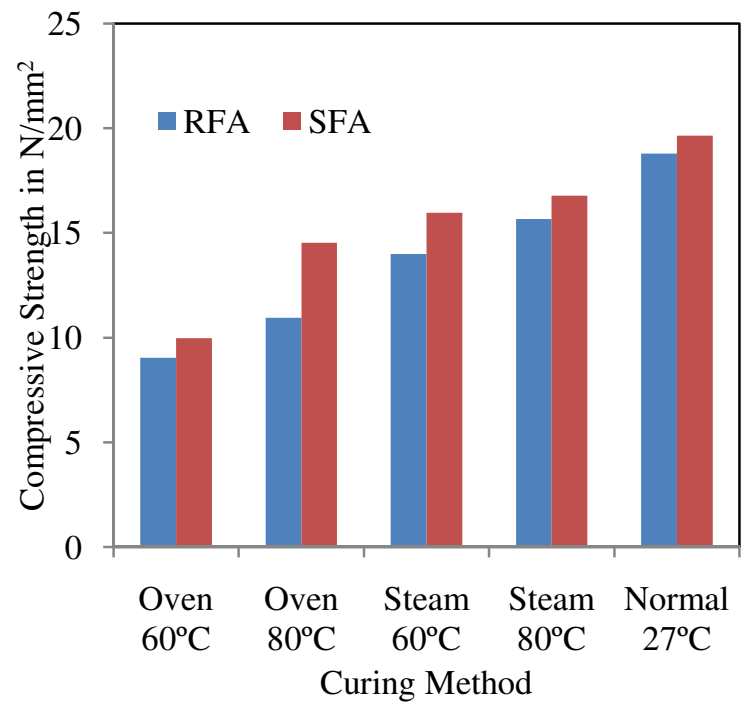

Figure 7: Compressive strength of $8 \mathrm{M}$ with Different curing Methods at 28 days

Similarly, the SFA mortar cubes prepared in $6 \mathrm{M}$ solution and cured at $60^{\circ} \mathrm{C}$ and $80^{\circ} \mathrm{C}$ in steam gives $9 \%$ and $25 \%$ higher compressive strength compared to RFA specimens. The SFA mortar cubes prepared in $8 \mathrm{M}$ steam cured at $60^{\circ} \mathrm{C}$ and $80^{\circ} \mathrm{C}$ in steam show $12 \%$ and $7 \%$ higher compressive strengths compared to RFA specimens.

\subsection{Effect of Method of Curing and Fineness of Fly Ash on Cube Compressive Strength}

The steam cured specimens gave a higher average compressive strength for RFA than FFA for the same molar ratio. The 28 day compressive strength test results is presented in (Figure 8). From the test results, it is observed that the compressive strength is increased in normal curing compare to the steam curing and oven curing. By comparing oven curing, the steam curing shows higher strength. The steam curing specimens strength is increased due to the polymerization process is done minimum water evaporation is occur. But in oven curing due to high temperature water evaporation is more. So the strength gain is more for steam cured specimens prepared with $8 \mathrm{M}$ concentration [22]. However the samples cured at ambient temperatures showed a higher 28day compressive strength than the other methods of curing. 


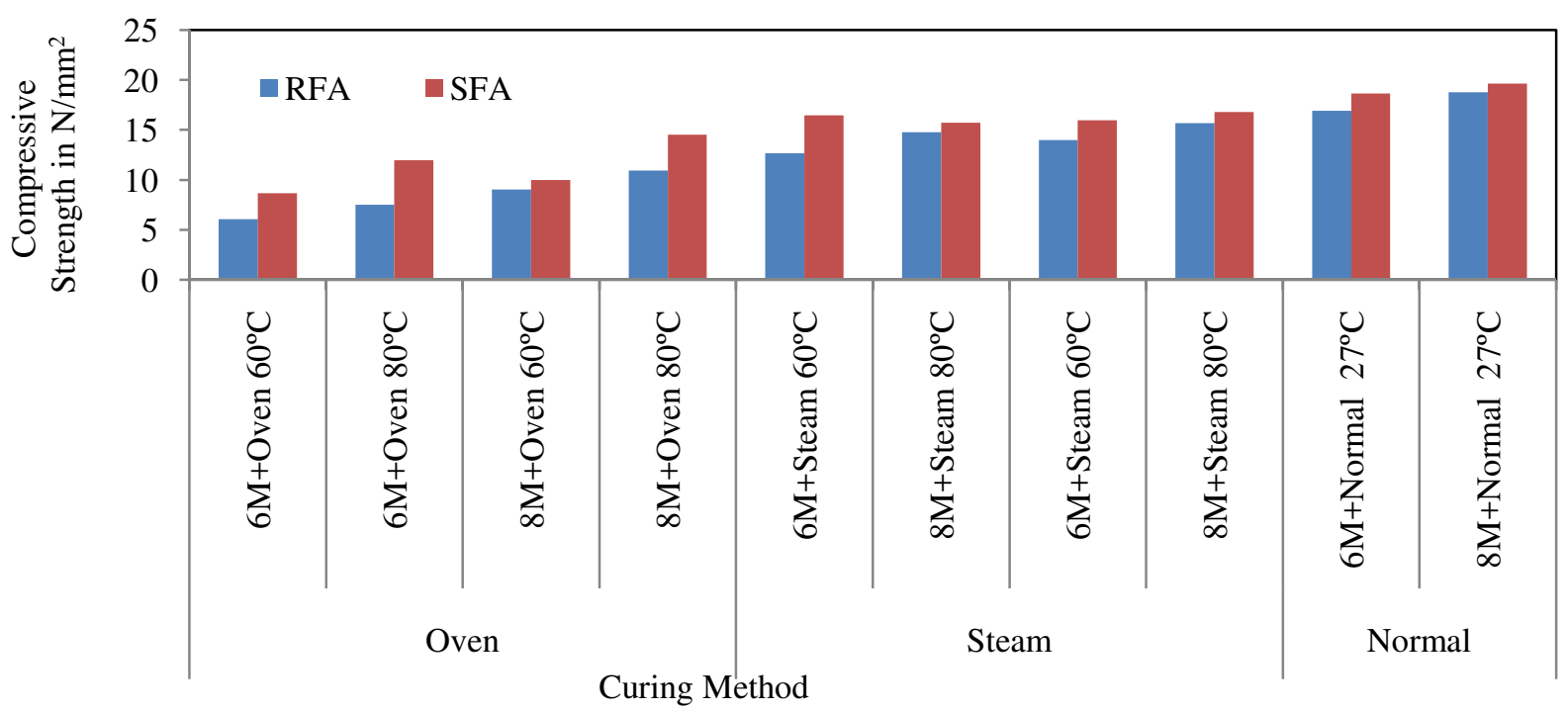

Figure 8: Compressive strength or mortar specimens with different curing methods and particle size reduction

\subsection{SEM images of RFA and SFA samples}

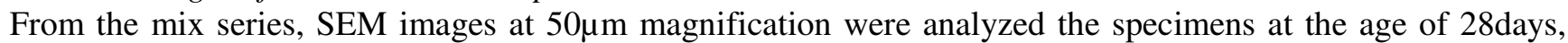
which showed highestcompressive strength were taken as a optimum mix proportions for SEM analysis. Images of RFA mortar specimens prepared with $8 \mathrm{M}$ solution at normal curing and SFA with $8 \mathrm{M}$ solution with normal curing at 28 days is presented in (Figure 9 and 10).

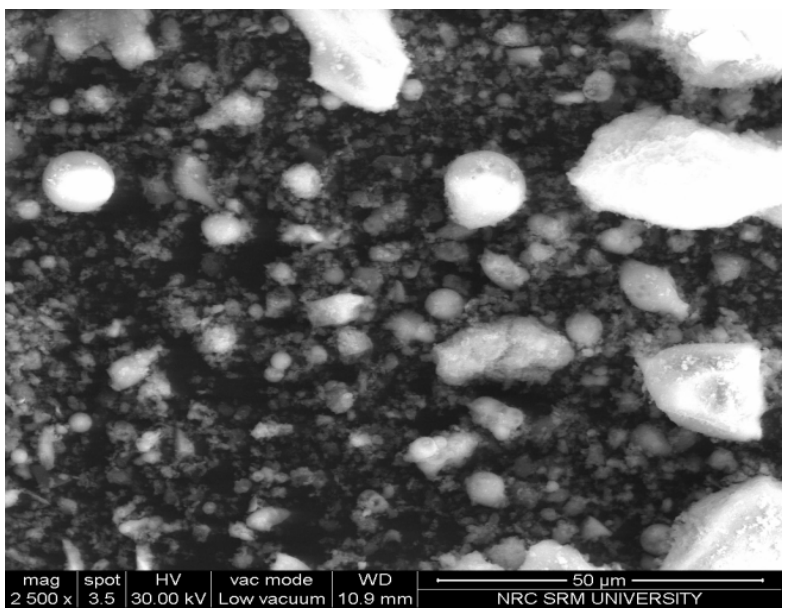

Figure 9: SEM image of RFA samples with $8 \mathrm{M}$ solution

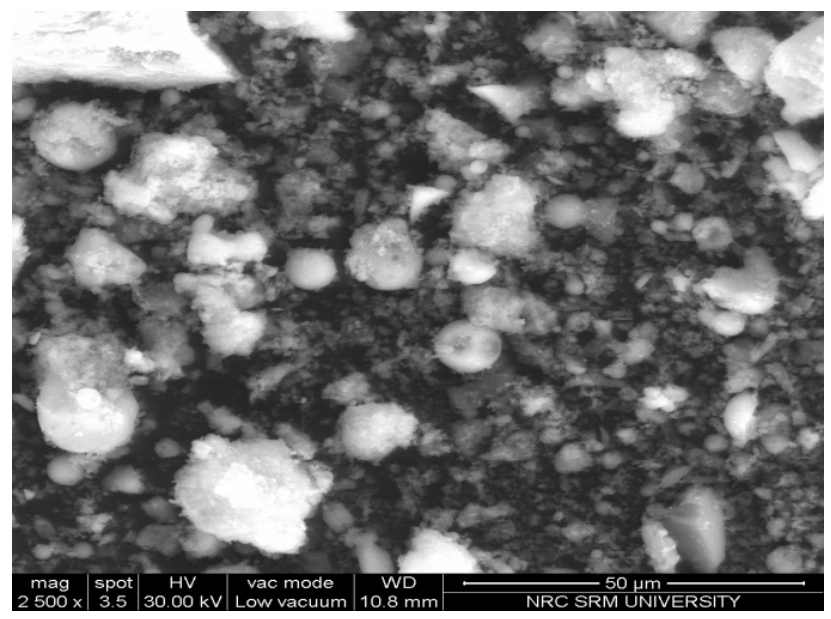

Figure 10: SEM image of SFA samples with 8M solution

The SEM pictures show that for the RFA test the smallest particle size measured was $162.7 \mathrm{~nm}$. For the fly ash test sieved utilizing $45 \mu$ sieve the smallest particle size noticed is $106.4 \mathrm{~nm}$. [23, 24]. The effect of presence of smaller sized particles observed in 45micron sieved fly ash is evident in the increased compressive strength.

\subsection{X-Ray Diffraction Analysis}

$\mathrm{X}$-ray diffraction is used to find the crystallite size of the phases of RFA and SFA samples, the results of which is shown in (Figure 11).PANalytical ' $\mathrm{X}$ ' Pert PRO diffractometer using $\mathrm{Cu}-\mathrm{K} \alpha$ radiation $(\lambda=1.54056 \AA)$ at an accelerating voltage of $40 \mathrm{kV}$ and a current of $30 \mathrm{~mA}$ is used. XRD measurement showing phases present (peak position), phase concentrations(peak intensity), amorphous content (background hump) and crystallite size(peak width) is done.The samples were scanned at a step size of 0.017 ( ${ }^{\circ} 2$ Theta) in the $2 \theta$ range from $5^{\circ}$ to $100^{\circ}$. The XRD patterns works on the principle of Braggs law: $\mathrm{n} \lambda=2 \mathrm{~d} \sin \Theta$. Comparisons of XRD powder pattern of the samples with RFA and SFA after 28 days of hydration shows that this similar peak present in both samples. This is, indeed, evident from the increased amorphous hump present below the crystalline peaks at both samples [25]. 


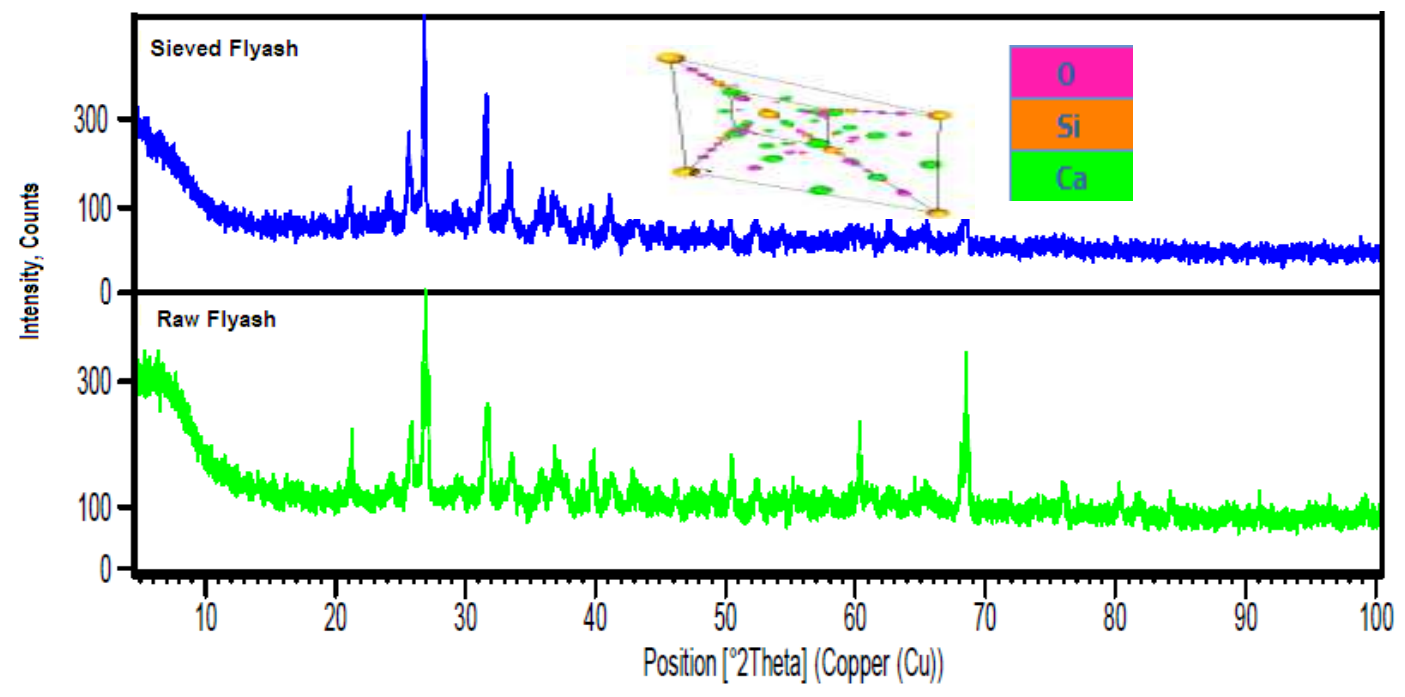

Figure 11: X-Ray Diffractogram of Raw Fly Ash and Sieved Fly Ash

\section{Conclusions}

From the detailed tests conducted by varying particle size, curing method, temperature, and concentration of alkaline solutions the following conclusions were drawn.

$>$ Decrease in particle size affects the compressive strength development. Specimens prepared with SFA gained higher compressive strength than RFA specimens.

$>$ The water demand is more for RFA sample compare to the SFA samples in both $6 \mathrm{M}$ and $8 \mathrm{M}$ solution.

$>$ Specimens prepared with $8 \mathrm{M}$ molar concentration of alkaline base gives high compressive strength values under various curing conditions compare with $6 \mathrm{M}$ solution.

$>$ Steam Curing brought about higher compressive strength improvement compared to oven curing and normal curing for samples prepared for both raw fly ash and sieved fly ash particles.

$>$ Curing at elevatedresulted in higher initial strength at compared to normal curing.

$>$ By comparing raw fly ash and sieved fly ash on both oven and steam curing at $80^{\circ} \mathrm{C}$ brought about higher compressive strength than $60^{\circ} \mathrm{C}$ temperature curing

$>$ Further increase in activator concentrations and use of finer particles can result in higher strengths. Geoploymer mortar / concrete can be a viable option for manufacture of precast products.

\section{Acknowledgment}

The authors wish to thank Nano Technology Research Centre and Department of Physics and Nano Technology, SRM University, Kattankulathur for their help to conduct Microstructural studies.

\section{References}

1. A. Fernandez-Jime nez, A. Palomo, M. Criado,Cem. Concr. Res., 35 (2005) 1204-1209.

2. K. Vijai, R.Kumutha, B.G. Vishnuram, Int. J. Phys. Sci., 5 (2010) 1419-1423.

3. HasanGhasemzadeh, EsmatAkbari Jalalabad, Int. Jour. Civ. Eng., 9 (2011) 224-229.

4. Mohd Mustafa Al Bakri1, H. Mohammed, H. Kamarudin, I. KhairulNiza, Y. Zarina, J. Eng. Tech. Res., 3 (2011) 1-4.

5. Deepak Ravikumar, SulaphaPeethamparan, Narayanan Neithalath, Cem. Conc. Comp, 3 (2010) 399-410.

6. HardjitoDjwantoro, Chua Chung Cheak, Carrie Ho Lee Ing, Jou. Mod. App. Sci., 2 (2008) 4.

7. N. Ravindra, Thakur,SomnathGhosh,ARPN J. Eng. App. Sci., 4 (2009) 4.

8. M. Schneider, M. Romer,M. Tschudin,H. Bolio, Cem. Concr. Res.,41 (2011) 642-650.

9. K. Thomas Paul, Satpathy, I. Manna, K. K. Chakraborty, G. B. Nando, Nanoscale Res Lett, 2 (2007) 397.

10. E. Morten, Simonsen, Camilla Sønderby, Zheshen Li, G. Erik, Søgaard., J Mater Sci, 44 (2009) 2079-2088.

11. M. A. OthumanMydin, N. A. Rozlan, S. Ganesan, J. Mater. Environ. Sci. 6 (2015) 407-411

12. A. S. Benosman, H. Taïbi, M. Mouli, Y. Senhadji, M. Belbachir, I. M. Bahlouli, D. Houivet, J. Mater. Environ. Sci. 6 (2) (2015) 559-571 
13. Anurag Mishra, Deepika Choudhary, Namrata Jain, Manish Kuma, NidhiSharda, Durga Dutt, ARPN J. Eng. App. Sci., 3 (2008) 1.

14. D. Bondar, C.J. Lynsdale, A.A. Ramezanianpour, 2nd International Conference on Concrete \& Development, 1 (2005) 001.

15. A. Allahverdil, E. NajafiKani, Int. Jour. Civ. Eng., 7 (2009) 154-160.

16. Standard Specification for Coal Fly Ash and Raw or Calcined Natural Pozzolan for Use in Concrete. ASTM C618. American Society for Testing and Materials.

17. Indian Standard Specification for Standard for testing cement -Specification, IS: 650-1991.Bureau of Indian Standards; New Delhi.

18. Indian Standard Specification for method of physical tests for hydraulic cement. IS: 4031-14, 1988, Bureau of Indian Standards, New Delhi.

19. American Society for Testing and Materials. ASTM C109/C109M- 99, 2001:,Annual book of ASTM Standards, Philadelphia.

20. A. Allahverdi, B. Shaverdil, E. NajafiKani, Int. Jour. Civ. Eng.,8 (2010) 304-314.

21. SerdarAydın, ÇaglayanKaratay, BülentBaradan,J.Pow. Tech., 197 (2010) 68-72.

22. Xu H., van Deventer., Int. Jou. Min. Pro., 59 (2000) 247-66.

23. A. Allahverdi, M. Mahinroosta1, Int. Jour. Civ. Eng.,12 (2015) 481-487.

24. A. Allahvedi, H. Hashemi, Int. Jour. Civ. Eng., 13 (2015) 380-387.

25. N. Kaid, M. Cyr, H. Khelafi, Int. Jour. Civ. Eng., 13 (2015) 444-454.

(2018) ; http://www.jmaterenvironsci.com 